\title{
Applying the Newman-Peacock Prognostic System to a Portuguese Obstetrical Population - A Useful Tool?
}

\section{Utilização do modelo de prognóstico Newman-Peacock numa população obstétrica portuguesa - uma ferramenta útil?}

\author{
Rita Mendes Silva ${ }^{1}$ Nuno Clode $^{2}$ \\ 1 Obstetrics and Gynecology University Department/Clinic, Centro \\ Hospitalar Lisboa Norte, Hospital Universitário de Santa Maria, \\ Lisboa, Portugal \\ 2 Obstetrics and Gynecology University Department/Clinic, Centro \\ Hospitalar Lisboa Norte, Hospital Universitário de Santa Maria, \\ Faculdade de Medicina da Universidade de Lisboa, CAM - Centro \\ Académico de Medicina de Lisboa, Lisboa, Portugal \\ Rev Bras Ginecol Obstet 2018;40:4-10.
}

\begin{abstract}
Address for correspondence Rita Mendes Silva, MD, Departamento/ Clínica Universitária de Obstetrícia e Ginecologia, Centro Hospitalar Lisboa Norte, Hospital Universitário de Santa Maria, Av. Prof. Egas Moniz, 1649-035 Lisboa, Portugal (e-mail: ritaimsilva@gmail.com).
\end{abstract}

\begin{abstract}
Keywords

- Newman-Peacock prognostic system score

- external cephalic version

- breech presentation

- vaginal delivery
\end{abstract}

Background External cephalic version (ECV) is a maneuver that enables the rotation of the non-cephalic fetus to a cephalic presentation. The Newman-Peacock (NP) index, which was proposed by Newman et al. in a study published in 1993, was described as a prediction tool of the success of this procedure; it was validated in a North-American population, and three prognostic groups were identified.

Purpose To evaluate the value of the NP score for the prediction of a successful ECV in a Portuguese obstetrical population, and to evaluate maternal and fetal safety.

Methods We present an observational study conducted from 1997-2016 with pregnant women at 36-38 weeks of pregnancy who were candidates for external cephalic version in our department. Demographic and obstetrical data were collected, including the parameters included in the NP index (parity, cervical dilatation, estimated fetal weight, placental location and fetal station). The calculation of the NP score was performed, and the percentages of success were compared among the three prognostic groups and with the original study by Newman et al. The performance of the score was determined using the Student $t$-test, the Chi-squared test, and a receiver operating characteristic (ROC) curve. Results In total, 337 women were included. The overall success rate was of $43.6 \%$. The univariate analysis revealed that multiparity, posterior placentation and a less engaged fetus were factors that favored a successful maneuver $(p<0.05)$. Moreover, a higher amniotic fluid index was also a relevant predictive factor $(p<0.05)$. The Newman-Peacock score had a poorer performance in our population compared with that of the sample of the original study, but we still found a positive relationship between higher scores and higher prediction of success $(p<0.001)$. No fetal or maternal morbidities were registered. received

January 30, 2017

accepted

June 26, 2017

published online

August 28, 2017
DOI https://doi.org/

$10.1055 / \mathrm{s}-0037-1606243$.

ISSN $0100-7203$.
Copyright $\odot 2018$ by Thieme Revinter

Publicações Ltda, Rio de Janeiro, Brazil

License terms

c) $(1) \$$ 


\section{Resumo}

\author{
Palavras-chave \\ - modelo de \\ prognóstico \\ Newman-Peacock \\ - versão cefálica \\ externa \\ - apresentação pélvica \\ - parto vaginal
}

Conclusions The Newman-Peacock score had a poorer performance among our population compared to its performance in the original study, but the results suggest that this score is still a useful tool to guide our clinical practice and counsel the candidate regarding ECV.

Âmbito A versão cefálica externa (VCE) é uma manobra que permite a obtenção de uma apresentação cefálica em fetos não-cefálicos. O índice de Newman-Peacock (NP), proposto por Newman et al em um estudo publicado em 1993, foi descrito como preditivo do sucesso desta manobra; ele foi validado numa população norte-americana, e três grupos de prognóstico diferentes foram identificados.

Objectivo Avaliação do valor preditivo do índice de NP para o sucesso da VCE numa população obstétrica portuguesa, bem como da segurança materno-fetal.

Métodos Foi realizado no nosso departamento um estudo observacional entre 19972016 em grávidas candidatas a VCE entre as 36 e as 38 semanas de gravidez. Foram colhidos dados demográficos e obstétricos, incluindo os parâmetros incluídos no índice de NP (a paridade, a dilatação cervical, a estimativa do peso fetal, a localização placentária e a altura da apresentação fetal). A pontuação das candidatas de acordo com o índice de NP e a percentagem de sucesso da VCE foram comparadas entre os três grupos de prognóstico, e também com o estudo original de Newman et al. O desempenho deste índice foi avaliado recorrendo aos testes $t$ de Student, qui-quadrado e curva receiver operating characteristic (ROC).

Resultados Foram incluídas 337 mulheres. A taxa de sucesso da manobra foi de 43,6\%. A análise univariada mostrou que a multiparidade, a placentação posterior e uma apresentação não encravada foram favoráveis para o sucesso do procedimento $(p<0,05)$. Adicionalmente, um maior índice de líquido amniótico revelou-se também como um fator preditivo significativo $(p<0,05)$. O índice de Newman-Peacock apresentou um desempenho inferior na nossa população comparativamente à sua descrição original, porém continuou a verificar-se uma relação positiva entre pontuações mais elevadas e uma maior percentagem de sucesso $(p<0,001)$.

Conclusão No nosso trabalho, o índice de Newman-Peacock apresentou um valor preditivo inferior comparativamente ao estudo original, porém os resultados mostram que se mantém uma ferramenta com utilidade para a prática clínica e para o aconselhamento das candidatas a versão cefálica externa.

\section{Introduction}

There are many concerns regarding a planned vaginal breech labor, particularly after the Term Breech Trial by Hannah et $\mathrm{al}^{1}$, which suggested a worse fetal outcome on the vaginal birth setting and, since then, a worldwide rise on cesarean sections (C-sections) in singleton term breech pregnancies has been observed. External cephalic version (ECV) at or near term is a $\mathrm{safe}^{2}$ and simple procedure with a reasonable success rate on converting non-cephalic presentation fetuses into cephalic ones, lowering the need for a C-section for this indication. Some concerns apply to this procedure, as there is a known risk of fetal bradycardia, placental abruption, preterm labor, umbilical cord prolapse and rupture of membranes. However, all of these complications are rare (with rates $<1 \%$ ), and do not cause a significant rise in morbidity and mortality; therefore, this procedure remains highly recommended for a breech presented fetus according to obstetrical associations world- wide, ${ }^{3}$ provided that it is performed in a place where a prompt cesarean delivery can be executed.

The success rate of the ECV procedure varies among groups, ${ }^{4-8}$ ranging from $16 \%$ to $100 \%$, with a pooled success rate of $58 \%{ }^{3}$ In 1993 , Newman et al ${ }^{4}$ proposed a score system that includes five parameters: parity, dilatation, estimated fetal weight, placental location and station. This score aimed to predict the probability of the success of the procedure; it was applied prospectively in 286 patients in a North-American setting, and 3 groups with different rates of success were identified. Great multipara, absence of dilatation, bigger fetus, lateral/fundal placenta, and station $\leq-3$ are aspects that contribute to a higher score and, therefore, a likely successful procedure. To our knowledge, there is only one published study about the performance of this prognostic system in a Pakistani obstetrical setting of 116 women, showing high failure rates regarding scores $\leq 3(93.8 \%$ ), and a similar failure rate regarding higher scores (40-46\%). ${ }^{9}$ Considering the potential benefit 
of a successful ECV, but also the possible, although unlikely, adverse events, a good predictive score is of great value.

\section{Objectives}

We aimed to evaluate the predictive value of the scoring system proposed by Newman and Peacock for the prediction of a successful ECV in our population. Our secondary goal was to evaluate the success rate and maternal and fetal safety.

\section{Methods}

We conducted an observational study applying the Newman-Peacock prognostic system to all pregnant women who were candidates for ECV in our department from 1997 to September 2016. The candidates for ECV were pregnant women on week 36-38 of gestation, with singleton breech fetuses and medically supervised pregnancies. The ECV was not performed in the presence of abnormal placentation, formal indication for C-section, vasa previa, third trimester bleeding, non-reactive non-stress test, oligohydramnios (amniotic fluid index $[\mathrm{AFI}] \leq 5 \mathrm{~cm}$ ), fetal growth restriction, fetal major malformation, uterine malformations, multiple gestation, and deflected fetal head. All of the women included in this study signed an informed consent form, and the procedure was performed in a hospital setting.

\section{Procedure}

Prior to attempting the ECV, all women were subjected to a non-stress test, which would have to present reactivity criteria and no decelerations. An ultrasound examination was performed to confirm the fetal presentation and position, the absence of nuchal cord, the quantification of amniotic fluid and the absence of head deflection. After emptying their bladders, the women went on supine position on a firm bed, and a vaginal examination was performed to evaluate the cervical dilatation and fetal head station, and tocolysis was started with intravenous infusion of $\beta$-adrenergic agonist (dilution of $5 \mathrm{mg}$ of salbutamol in $500 \mathrm{~mL}$ of dextrose saline $5 \%$ ), at an initial rate of $15 \mathrm{~mL} / \mathrm{h}$, titrated in steps of 15 $\mathrm{mL} / \mathrm{h}$ each 20 minutes until the fetal parts were easily palpable and/or the maternal heart rate was $\geq 100 \mathrm{bpm}$.

The ECV attempts were performed by one of three experienced obstetricians who remained at the right side of the pregnant (except in cases in which the obstetrician had a dominant left hand). The technique used was as follows: 1) disengagement of the fetal breech with the fingers of the operator's right hand, bringing it above the symphysis and pulling it to one of the flanks; and 2) with the palm of his left hand, referral of the fetal head toward the maternal pelvis simultaneously with progressive elevation of the fetal pelvis. The direction of the fetal movement should be similar to a forward or backward roll.

The indications for the interruption of the procedure were: excessive maternal discomfort, and evidence of fetal bradycardia and/or three previous unsuccessful attempts.

Fetal presentation was always confirmed in the end by ultrasound, and a cardiotocographic record was obtained before discharge. Anti-D gamma globulin was administered to all Rh-negative women at risk of immunization.

\section{Data Record}

On each attempt, maternal and obstetrical data was collected (age, race/ethnicity, weight, height, gestational age, fetal situation and presentation, and AFI), covering the five parameters included in the Newman-Peacock score (-Table 1): parity, estimated fetal weight, placental location, cervical dilatation, and fetal station.

\section{Statistical Analysis}

The statistical analysis was performed using the the IBM SPSS Statistics (IBM Corp., Armonk, NY, US) software, version 24. The differences between the groups were evaluated using the Student $t$-test, the $U$ Mann-Whitney test and analysis of variance (ANOVA) for the continuous variables, and the Chisquared and Fisher tests for the categorical variables. A receiver operating characteristic (ROC) curve was plotted to evaluate the performance of the score. An alpha value of 0.05 was considered statistically significant, and all tests were two-sided.

\section{Results}

Between 1997 and 2016, 352 women underwent an ECV trial at our department. A total of 14 women were excluded from our study due to transverse lies and/or missing data. Among the remaining 337 women, we had a success rate of $43.6 \%$ $(n=147)$.

- Table 2 summarizes the demographics of our sample divided by the outcome of the ECV. The majority of the women was Caucasian (89.7\%), the mean maternal age was 30 (17-44) years, and most women were nulliparous (66.1\%).

Regarding the remaining data, there was no statistical difference regarding gestational age, estimated fetal weight, type of breech and cervical dilatation. By contrast, the placental location showed significant differences between the groups, and posterior placentas were a favorable sign. Moreover, the fetal station appeared as a relevant predictive factor, favoring less engaged fetuses. The mean AFI was slightly higher for the successful group (14 cm versus $12 \mathrm{~cm}$ ), and this difference was statistically significant ( $p=0.002$ ).

Failed procedures were interrupted mostly after unsuccessful attempts (70.9\%). Only 10 cases of fetal bradycardia

Table 1 Newman-Peacock scoring system as originally published ${ }^{4}$

\begin{tabular}{|l|l|l|l|}
\hline & $\mathbf{0}$ & $\mathbf{1}$ & $\mathbf{2}$ \\
\hline Parity & 0 & 1 & $\geq 2$ \\
\hline Dilatation & $\geq 3 \mathrm{~cm}$ & $1-2 \mathrm{~cm}$ & $0 \mathrm{~cm}$ \\
\hline $\begin{array}{l}\text { Estimated fetal } \\
\text { weight }\end{array}$ & $<2,500 \mathrm{~g}$ & $2,500-3,500 \mathrm{~g}$ & $>3,500 \mathrm{~g}$ \\
\hline $\begin{array}{l}\text { Placental } \\
\text { location }\end{array}$ & anterior & posterior & $\begin{array}{l}\text { lateral/ } \\
\text { fundal }\end{array}$ \\
\hline Station & $\geq-1$ & -2 & $\leq-3$ \\
\hline
\end{tabular}


Table 2 Descriptive statistics of the predictors for the successful and unsuccessful ECV groups and the results of the univariate analysis comparing ECV success versus failure

\begin{tabular}{|c|c|c|c|c|}
\hline & Total sample & ECV success & ECV failure & $p$ \\
\hline \multicolumn{5}{|l|}{ Race/ethnicity } \\
\hline Caucasian & $299(89.8 \%)$ & $130(43.1 \%)$ & $169(56.9 \%)$ & \multirow[t]{3}{*}{0.064} \\
\hline Black & $29(8.7 \%)$ & $13(44.8 \%)$ & $16(55.2 \%)$ & \\
\hline Others & $5(1.8 \%)$ & $4(80 \%)$ & $1(20 \%)$ & \\
\hline Age (years) & & $30.2( \pm 4.6)$ & $30.4( \pm 5.1)$ & 0.609 \\
\hline \multicolumn{5}{|l|}{ Parity } \\
\hline Nulliparous & $224(66.5 \%)$ & $86(38.4 \%)$ & $138(61.6 \%)$ & \multirow[t]{2}{*}{0.005} \\
\hline Multiparous & $113(33.5 \%)$ & $61(54 \%)$ & $52(46 \%)$ & \\
\hline Body mass index $\left(\mathrm{kg} / \mathrm{m}^{2}\right)$ & & $26.2( \pm 4.3)$ & $26.7( \pm 4.8)$ & 0.346 \\
\hline \multicolumn{5}{|l|}{ Gestational age } \\
\hline 36 weeks & $132(39.3 \%)$ & $58(43.9 \%)$ & $74(56.1 \%)$ & \multirow[t]{3}{*}{0.391} \\
\hline 37 weeks & $134(39.9 \%)$ & $64(47.8 \%)$ & $70(52.2 \%)$ & \\
\hline 38 weeks & $70(20.8 \%)$ & $25(35.7 \%)$ & $45(64.3 \%)$ & \\
\hline \multicolumn{5}{|l|}{ Fetal weight } \\
\hline$<2,500 \mathrm{~g}$ & $50(14.8 \%)$ & $18(36.0 \%)$ & $32(64 \%)$ & \multirow[t]{3}{*}{0.242} \\
\hline $2,500-3,500 \mathrm{~g}$ & $275(81.6 \%)$ & $124(45.1 \%)$ & $151(54.9 \%)$ & \\
\hline$>3,500 \mathrm{~g}$ & $12(3.6 \%)$ & $5(41.7 \%)$ & $7(58.3 \%)$ & \\
\hline \multicolumn{5}{|l|}{ Type of breech } \\
\hline Complete & $38(11.3 \%)$ & $15(39.5 \%)$ & $23(60.5 \%)$ & \multirow[t]{3}{*}{0.787} \\
\hline Frank & $278(82.7 \%)$ & $124(44.6 \%)$ & $154(55.4 \%)$ & \\
\hline Footling & $20(6 \%)$ & $8(40 \%)$ & $12(60 \%)$ & \\
\hline \multicolumn{5}{|l|}{ Placental position } \\
\hline Anterior & $114(33.8 \%)$ & $40(35.1 \%)$ & $74(64.9 \%)$ & \multirow[t]{3}{*}{$0.023^{\S}$} \\
\hline Posterior & $132(39.2 \%)$ & $69(52.3 \%)$ & $63(47.7 \%)$ & \\
\hline Fundal/lateral & $91(27.0 \%)$ & $38(41.8 \%)$ & $53(58.2 \%)$ & \\
\hline \multicolumn{5}{|l|}{ Station } \\
\hline$\geq-1$ & $23(6.8 \%)$ & $5(21.7 \%)$ & $18(78.3 \%)$ & \multirow[t]{3}{*}{$<0.001$} \\
\hline-2 & $130(38.6 \%)$ & 37 (28.5\%) & 93 (71.5\%) & \\
\hline$\leq-3$ & $184(54.6 \%)$ & $105(57.1 \%)$ & $79(42.9 \%)$ & \\
\hline \multicolumn{5}{|l|}{ Cervical dilatation } \\
\hline$\geq 3 \mathrm{~cm}$ & $4(1.2 \%)$ & $2(50 \%)$ & $2(50 \%)$ & \multirow[t]{3}{*}{0.965} \\
\hline $1-2 \mathrm{~cm}$ & $81(24.0 \%)$ & $35(43.2 \%)$ & $46(56.8 \%)$ & \\
\hline $0 \mathrm{~cm}$ & $252(74.8 \%)$ & $110(43.7 \%)$ & $142(56.3 \%)$ & \\
\hline Amniotic fluid index $(\mathrm{cm})$ & & $13.9( \pm 4.2)$ & $12.1( \pm 3.9)$ & 0.002 \\
\hline
\end{tabular}

Notes: The categorical variables are represented by $\mathrm{n}(\%)$, and the continuous variables are represented by mean \pm standard deviation. Significant $p$ values are in bold;

$\S$ differences found between anterior versus posterior placentation (fundal/lateral placentation does not differ from anterior or posterior placentation);

${ }_{\ddagger}^{\ddagger}$ differences found between station $\leq-3$ versus lower ones (station -2 does not differ from $\geq-1$ ).

were registered, with full spontaneous recoveries, without the need for urgent obstetric intervention. We observed no other fetal and/or maternal complications.

When evaluating the mean Newman-Peacock score for each group of ECV, we could observe a slightly statistically significant difference, with a higher score for the successful group ( 5.82 versus $5.16 ; p=0.000$ ), as shown in - Table 3 . As Newman et $\mathrm{al}^{4}$, we found that the higher the score, the higher the prediction of success (-Fig. 1). Moreover, stratifying our sample into 3 groups, similar to the ones defined by Newman et al( $|0-4|,|5-7|,|8-10|)$, the prediction rates differed among the three groups, with a statistical difference found between 
Table 3 Prediction of success using the Newman-Peacock score, (A) comparison of the global mean values of the Newman-Peacock score (mean standard deviation) in our sample between the successful and unsuccessful groups; (B) comparison of the percentage of success/failure in our sample versus the original study published by Newman et al ${ }^{4}$ by group. The Chi-squared test was performed regarding the results of our sample

\begin{tabular}{|c|c|c|c|c|c|}
\hline (A) & ECV success & ECV failure & \multicolumn{3}{|l|}{$p$} \\
\hline NP score & $5.82 \pm 1.26$ & $5.16 \pm 1.21$ & \multicolumn{3}{|l|}{$<0.001^{\S}$} \\
\hline \multirow[t]{2}{*}{ (B) } & ECV success & ECV failure & \multicolumn{3}{|l|}{$p$} \\
\hline & Present study & Original NP & Present study & Original NP & \\
\hline Group 1 (score 8-10) & $12(70.6 \%)$ & $(88 \%)$ & $5(29.4 \%)$ & $(12 \%)$ & \multirow[t]{3}{*}{$<0.001^{t}$} \\
\hline Group 2 (score 5-7) & $116(47.3 \%)$ & $(65 \%)$ & $129(52.7 \%)$ & $(35 \%)$ & \\
\hline Group 3 (score $0-4$ ) & 19 (25.3\%) & $(22 \%)$ & 56 (74.7\%) & $(78 \%)$ & \\
\hline
\end{tabular}

Abbreviations: ECV, external cephalic version; NP, Newman-Peacock.

§Student $t$-test;

${ }^{\ddagger}$ Chi-squared test. In our data, differences were found between group 1 versus the others (group 2 does not statistically differ from group 3 Bonferroni method).

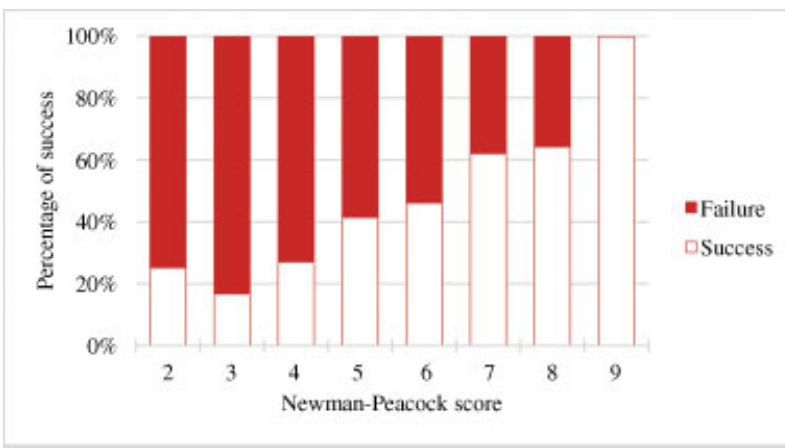

Fig. 1 Percentages of success in our sample, according to the Newman-Peacock score.

group 1 versus the others, with higher success rates associated to higher scores $(-$ Table 3 ). In other words, the cases with a score $\geq 8$ showed significant higher probability of success compared with cases with lower scores. Generally, our numbers were not far distant from the ones originally described by Newman et al, but with a lower power to predict a successful maneuver.

In order to objectively measure the prediction power of the Newman-Peacock score for our sample, a ROC curve was plotted (-Fig. 2). The area under the curve was 0.642 (95\% confidence interval [95\%Cl]: $0.583-0.701$ ) for the prediction of success, which represents a poor performance.

\section{Discussion}

Our work aimed to understand the prediction value of the Newman-Peacock system in our Portuguese obstetrical setting. This observational study had a similar ECV success rate compared with the published data, although it was lower compared with the rate obtained by Newman et al (43\% versus 65\%). Moreover, we had no adverse maternal or fetal outcomes, and that supports the opinion that the ECV is a safe procedure. Our study used a methodology that was

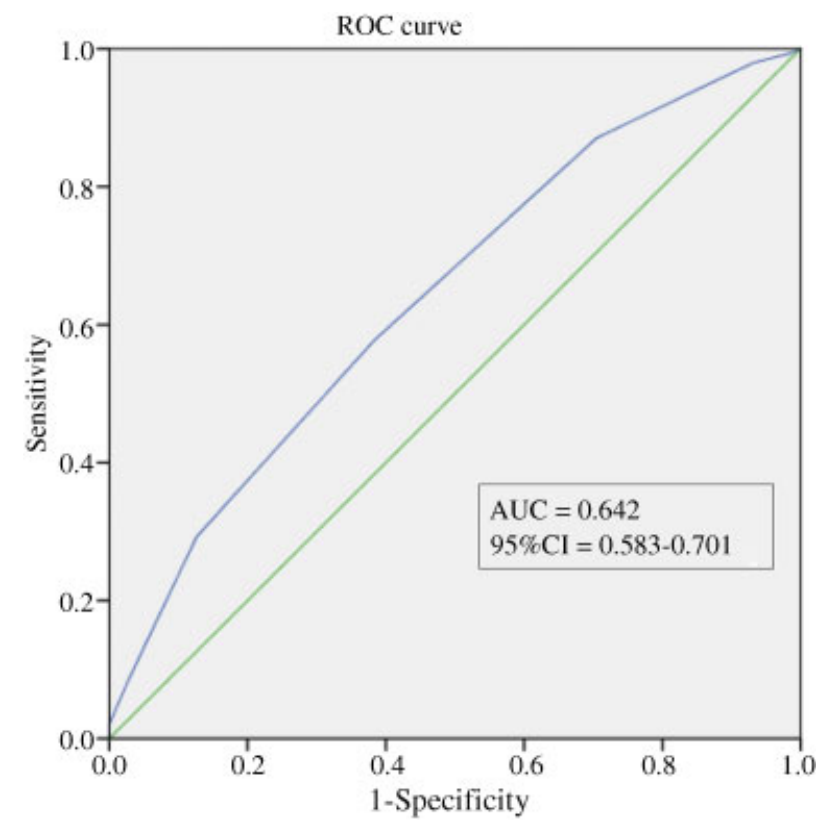

Fig. 2 ROC curve for the prediction of ECV success based on the Newman-Peacock score. Abbreviations: $95 \% \mathrm{Cl}, 95 \%$ confidence interval; AUC, area under the curve; ROC, receiver-operating characteristic.

very similar to the one used by Newman et $\mathrm{al}^{4}$, which is described in their original paper, but our sample size was larger. For that reason, all transverse lies were excluded from this study, and all our attempts were made under tocolysis to promote uterine relaxation, making the fetal head palpation and the execution of the maneuver easier, ${ }^{3,10,11}$ with no adverse reactions noted. Our data suggested that only the women with scores $\geq 8$ were more likely to have a successful attempt. The score had a worse discriminative power in our sample to predict the success of the ECV compared with the original description, and that could be related to population characteristics, which are not detailed in the Newman et $\mathrm{al}^{4}$ paper. Our data showed that posterior placentation had a 
higher success rate, which may be explained by a better grip of the fetus, but this was not found in the Newman et al study, in which lateral/fundal placentas had scores higher than the posterior ones. Still, we could verify that, in our sample, the higher the score obtained, the higher the percentage of success (with one exception for scores 2 and 3), and that enforces our opinion that the Newman-Peacock score has a role in the prediction of success.

The Newman-Peacock score includes five parameters of easy collection before a planned ECV procedure: parity, estimated fetal weight, cervical dilation, placental location and fetal station. Among these, multiparity, higher fetal estimated weight and anterior placental location have been most commonly mentioned as effective predictive factors of a successful attempt. ${ }^{5-8,10-13}$ Some possible explanations refer to the decreased uterine tone in multiparas, ${ }^{10}$ the bigger obstacle an anterior placenta might pose, or the easier rotation of a heavier baby. Meanwhile, we only found one study that included vaginal examination data, in which the fetal station was considered a predictor, but cervical dilatation was not. ${ }^{11}$ Our data suggested a clinical importance regarding parity, placental location and head station for the prediction of ECV success.

Many other factors have been mentioned as relevant to predict success. The AFI is among the most described predictive factors, along with fetal position, gestational age and maternal body mass index (BMI). ${ }^{5-8,10-14}$ The studies are controversial, with variables that are significant to some authors but not significant to others.

Several studies used a univariate or multivariate approach to identify the relevant predictors, and their heterogeneity was established in a systematic review published in 2015 . $^{15}$ Besides the Newman-Peacock score, another three simplified scoring indices that are easy to apply in the clinical practice have been proposed. In a small 2-phase study with 53 (observational phase) and then 88 (validation phase) women, Wong et $\mathrm{al}^{16}$ devised an index considering that a palpable head, the non-engagement of the fetus, symphysisfundal height and uterine relaxation were the most relevant predictors. Burgos et al ${ }^{17}$ published a larger 2-phase study in 2011 with 500 and then another 500 women, and suggested another index that only included parity, placental location, type of breech and amount of amniotic fluid, with a predictability of $73.8 \%$. Tasnim et $\mathrm{al}^{9}$ proposed a score that included BMI, parity, gestational age, type of breech and AFI as predictors, which were chosen after an observational phase study with 267 women, with a better prediction performance than the Newman-Peacock score, but without a prospective validation phase.

Our group conducted a prospective validation of an ECV score in a Portuguese obstetrical setting, which enabled us to better understand the feasibility of this score among our population. We included 337 women, which is, by our knowledge, the largest study testing the Newman-Peacock index, and the only one with a Portuguese population. This index was chosen given its popularity and ease of application, but it is far from perfect. In our sample, a predictive role of the AFI was also suggested, and this parameter probably should be incorporated in a better prognostic index for ECV, as also sustained by other workgroups.

The main strengths of our study are its sample size and its design, which enabled us to collect prospectively all the five parameters of the Newman-Peacock score among our women. The long period of data collection with different obstetricians performing the maneuver may have limited its success. Moreover, as the obstetricians were not blind to the clinical and ultrasound data, we cannot exclude a possible bias in the efforts to perform the ECV.

Although the ECV is an acceptably safe procedure, not every obstetrician is comfortable with its execution and/or referral. On the other hand, couples show concerns about the procedure. Therefore, although the Newman-Peacock score may not be a very accurate tool, in our opinion, it still stands as a useful tool to guide our practice and counsel our patients. A solid prognostic system would be of great value in this field.

\section{Conflict of Interests}

Authors declare no conflict, neither financial support.

\section{Contribution to Authorship}

Rita Silva Batista participated in the conception and design of the study, acquisition of data, analysis and interpretation of data, literature search, writing and editing. Nuno Clode participated in the conception and design of the study, acquisition of data, analysis and interpretation of data, and revision of important intellectual content.

\section{Acknowledgments}

We would like to acknowledge the residents of our department for their contribution in the acquisition of data.

\section{References}

1 Hannah ME, Hannah WJ, Hewson SA, Hodnett ED, Saigal S, Willan AR; Term Breech Trial Collaborative Group. Planned caesarean section versus planned vaginal birth for breech presentation at term: a randomised multicentre trial. Lancet 2000;356(9239): 1375-1383

2 Beuckens A, Rijnders M, Verburgt-Doeleman GH, Rijninks-van Driel GC, Thorpe J, Hutton EK. An observational study of the success and complications of 2546 external cephalic versions in low-risk pregnant women performed by trained midwives. BJOG 2016;123(03):415-423

3 American College of Obstetricians and Gynecologists' Committee on Practice Bulletins-Obstetrics. Practice Bulletin No. 161: external cephalic version. Obstet Gynecol 2016;127(02):e54-e61

4 Newman RB, Peacock BS, VanDorsten JP, Hunt HH. Predicting success of external cephalic version. Am J Obstet Gynecol 1993; 169(2 Pt 1):245-249, discussion 249-250

5 Aisenbrey GA, Catanzarite VA, Nelson C. External cephalic version: predictors of success. Obstet Gynecol 1999;94(5 Pt 1): 783-786

6 Kok M, van der Steeg JW, van der Post JA, Mol BW. Prediction of success of external cephalic version after 36 weeks. Am J Perinatol 2011;28(02):103-110

7 Mowat A, Gardener G. Predictors of successful external cephalic version in an Australian maternity hospital. Aust $\mathrm{N} \mathrm{Z} \mathrm{J} \mathrm{Obstet}$ Gynaecol 2014;54(01):59-63 
8 Ebner F, Friedl TW, Leinert E, et al. Predictors for a successful external cephalic version: a single centre experience. Arch Gynecol Obstet 2016;293(04):749-755

9 Tasnim N, Mahmud G, Javaid K, Malhotra N, Puri R. GNK-PIMS Score: a predictive model for success of external cephalic version. J South Asian Fed Obstet Gynaecol 2012;4(02):99102

10 Hutton EK, Hofmeyr GJ, Dowswell T. External cephalic version for breech presentation before term. Cochrane Database Syst Rev 2015;(07):CD000084

11 Indraccolo U, Graziani C, Di Iorio R, Corona G, Bonito M, Indraccolo SR. External cephalic version for singleton breech presentation: proposal of a practical check-list for obstetricians. Eur Rev Med Pharmacol Sci 2015;19(13):2340-2353

12 Burgos J, Melchor JC, Pijoán JI, Cobos P, Fernández-Llebrez L, Martínez-Astorquiza T. A prospective study of the factors associated with the success rate of external cephalic version for breech presentation at term. Int J Gynaecol Obstet 2011; 112(01):48-51

13 Ben-Meir A, Erez Y, Sela HY, Shveiky D, Tsafrir A, Ezra Y. Prognostic parameters for successful external cephalic version. J Matern Fetal Neonatal Med 2008;21(09):660-662

14 Tasnim N, Mahmud G, Khurshid M. External cephalic version with salbutamol - success rate and predictors of success. J Coll Physicians Surg Pak 2009;19(02):91-94

15 Velzel J, de Hundt M, Mulder FM, et al. Prediction models for successful external cephalic version: a systematic review. Eur J Obstet Gynecol Reprod Biol 2015;195:160-167

16 Wong WM, Lao TT, Liu KL. Predicting the success of external cephalic version with a scoring system. A prospective, two-phase study. J Reprod Med 2000;45(03):201-206

17 Burgos J, Cobos P, Rodriguez L, et al. Clinical score for the outcome of external cephalic version: a two-phase prospective study. Aust N Z J Obstet Gynaecol 2012;52(01):59-61 